\title{
Do Older Adults with HIV Have Distinctive Personal Networks? Stigma, Network Activation, and the Role of Disclosure in South Africa
}

\author{
Markus H. Schafer ${ }^{1}\left[\right.$ [ - Laura Upenieks ${ }^{2}$. Julia DeMaria ${ }^{1}$
}

Published online: 9 August 2020

(c) Springer Science+Business Media, LLC, part of Springer Nature 2020

\begin{abstract}
This study considers whether the personal networks of older South African people living with HIV (PLHIV) differ from those without HIV. Using recent survey data $(\mathrm{N}=5059)$, results suggest that PLHIV reported more core network members than their peers without HIV (IRR 1.08; 95\% CI 1.03, 1.13), but were equally likely to receive emotional support from network members $(1.21 ; 95 \%$ CI $0.93,1.58)$. PLHIV who had yet to disclose their serostatus were more likely than others to have friends and other non-kin in their core network $(B 0.08 ; 95 \%$ CI $0.02,0.13)$ and to maintain networks of non-overlapping members (OR 2.11; 95\% CI 1.33, 3.34). Even as HIV remains highly stigmatized in South Africa, PLHIV tend to maintain relatively large and supportive networks. Still, a sizeable proportion of PLHIV do not disclose their illness-these individuals disproportionately inhabit networks marked by non-kin and by high bridging potential.
\end{abstract}

Keywords HIV · Social networks · South Africa · Stigma

\section{Introduction}

People facing serious chronic health problems need dependable social contacts. Ill individuals with limited social networks and inadequate access to support report lower quality of life, show poorer disease management, and die sooner than their well-connected peers [1-3]. Recognizing these high stakes, researchers have devoted considerable attention to understanding how various diseases influence the form and function of people's networks [4-7].

Scholars identify two divergent social network processes that can accompany people's experience of chronic illness. Network activation contends that personal troubles-including serious disease-trigger purposive action intended to secure ameliorative resources [8-11]. The activation perspective implies a health-preserving process whereby illness prompts people to expand or reconfigure their networks to optimally deal with their disease. Social stigma represents a contrasting perspective. This framework recognizes that

Markus H. Schafer

markus.schafer@utoronto.ca

1 Department of Sociology, University of Toronto University of Toronto, 725 Spadina Avenue, Toronto, ON M5S 2J4, Canada

2 Department of Sociology, Baylor University, Waco, USA certain illnesses, HIV/AIDS above all, are perceived as morally discrediting and taint patients' identities [12-15]. This can have at least two implications for social networks. First, others often distance themselves from the disease sufferer, and second, people with the disease frequently internalize stigma and withdraw from others out of fear [12-14]. These processes ultimately leave the ill individual at risk of isolation and without needed social resources.

Existing research on HIV points to the viability of both stigma and activation processes [16]. One body of evidence suggests that people living with HIV (PLHIV) may be less socially connected than others. Recent estimates, for instance, suggest that nearly a third of older PLHIV in New York City have networks characterized by "isolation" (little contact with family, few friends), a percentage roughly equal to the prevalence of more connected "friend-centered" and "integrated" networks [17]. A recent meta-synthesis of qualitative research points to the commonality of disownment and rejection from immediate family members, relatives, and friends following diagnosis [18]. Social support deficits are often thought to accompany such isolation. Shippy and Karpiak report, for instance, that among a sample of older PLHIV in New York City, 57\% receive inadequate emotional support, while 78\% need more instrumental support [14].

On the other hand, some studies indicate that PLHIV maintain multifaceted networks that provide needed support. 
Upon receiving a diagnosis of HIV, for example, many older Finnish adults begin to actively establish new relationships with friends, especially with HIV support group members [19]. Several studies describe relatives and neighbors filling significant gaps in support networks, particularly after conflict or estrangement with former ties [20-22].

Existing literature points to two interrelated considerations relevant to stigma and activation processes that will inform the present analysis. First, studies highlight an important distinction between kin-based and voluntary (i.e., deliberately chosen, non-family) social ties. As with many serious health conditions, PLHIV often identify their spouse as a central supporter and companion [23, 24]. Adult children are also often activated as key members of the network [12, 25]. PLHIV that are non-partnered and without children, however, often rely most heavily on friends for support [26]. In some circumstances, incorporating voluntary ties in addition to- or in place of-family members can be a strategic response to stigma [24, 26, 27].

Second, prior studies reveal the importance of HIV disclosure in the maintenance and function of networks [28-32]. Indeed, the stigma of HIV has crucial implications for whether, how, and to whom people disclose having the condition. PLHIV are strategic when revealing their serostatus, often informing spouses, but commonly keeping the information from other immediate family members or friends [21, 30, 31]. From the numbers reported across different contexts, the vast majority of PLHIV appear to inform at least someone of their status (e.g., 95\% in [29]; 100\% in [31]).

\section{Hypotheses for Multiple Dimensions of the Personal Network}

\section{Competing Hypotheses}

The stigma argument posits that living with HIV/AIDS leads to deficits in personal network size (Hypothesis 1a) and availability of emotional support from network members (Hypothesis 2a) relative to living without HIV/AIDS. The basic activation argument, on the other hand, anticipates that PLHIV have larger personal networks (Hypothesis $1 b$ ) and a greater likelihood of receiving emotional support from network members (Hypothesis $2 b$ ) relative to others.

\section{Compatible Hypotheses}

Stigma and activation converge on similar expectations for whether those living with HIV/AIDS will differ from others with respect to presence of non-kin people in the network and with respect to network bridging potential. Nevertheless, disclosure of the condition is anticipated to differentiate the two theoretical perspectives with respect to these outcomes.
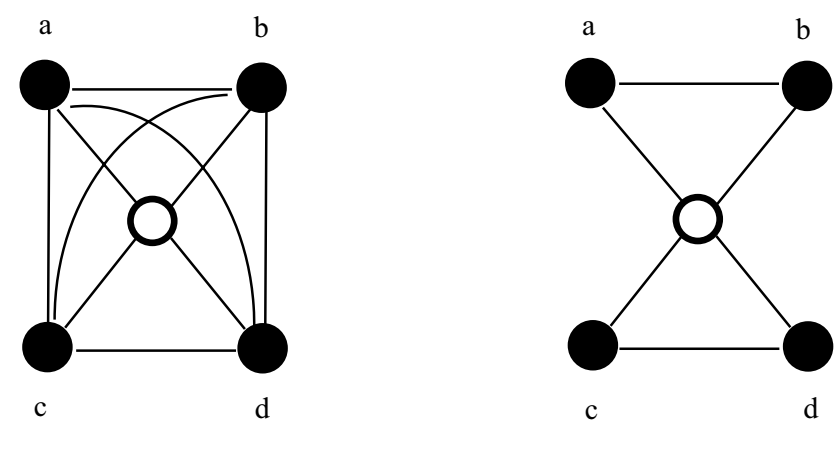

no bridging potential

bridging potential

Fig. 1 Illustrating network bridging potential. Note The focal individual (ego) is depicted by the middle, empty circle. Black circles depict members of ego's personal network. Lines depict relationships between actors in the network

First, we expect those living with HIV/AIDS to have a relatively high proportion of non-kin network members in their core networks (Hypothesis 3) and relatively high bridging potential (Hypothesis 4). By "bridging potential," we refer to situations where people maintain network ties between people who are themselves not directly connected and for whom exists no alternative intermediary. Figure 1 illustrates this concept graphically, distinguishing between an individual whose network members all know one another ("no bridging potential") and an individual with a subset of close ties who do not ("bridging potential"; e.g., network members A and $\mathrm{C}$ or $\mathrm{A}$ and $\mathrm{D}$ ).

From the perspective of network activation, non-kin ties represent network expansiveness beyond the primary social group. Kin members are often the most dependable care providers for those dealing with chronic health problems [33, 34], but ties to friends, neighbors, and others diversify networks and grant access to more information and resources [35]. Likewise, bridging potential in a network optimizes the availability of unique, non-redundant social resources. Someone who bridges non-overlapping groups will have a network configuration in which their connections are largely unable to control or obstruct the flow of information [36]. Such relational autonomy and empowerment could be important when dealing with sensitive health issues such as HIV/AIDS; someone with bridging potential could discretely seek and receive support to manage their illness, whereas those in fully interconnected networks risk monitoring and unwanted detection.

This reasoning also illustrates the applicability of stigma theory for Hypotheses 3 and 4. Non-kin relationships have the advantage of being voluntary, and so if people need nonjudgemental contacts, they likely seek out and retain them from the pool where they have greatest choice. This process would be all the more important to the extent that HIV/AIDS 
prompts expressions of shame in families [18]. By the same token, bridging potential is a structural arrangement optimal for stigmatized populations.

Though stigma and activation perspectives each motivate Hypothesis 3 and Hypothesis 4, there is arguably a stronger case for stigma in situations where network composition and bridging potential differ along certain lines of HIV/AIDS disclosure. Evidence that people's networks vary according to whether they reveal or conceal their condition would testify to the discrediting nature of HIV. Increasing one's share of non-kin network members and cultivating bridging potential could be a signal of network activation post-disclosure (to gain needed support or resources), just as these actions could be a response to prejudice (or could reflect that people share their serostatus when they are embedded in a network form most favorable to disclosure). Nevertheless, elevated non-kin composition and higher network bridging among non-disclosed PLHIV relative to individuals living without HIV would demonstrate the particularity of stigma over against network activation. This pattern would suggest that internalized or potential stigma leads PLHIV to inhabit distinctive network forms where threat of detection and censure is curtailed. Activation theory, in contrast, offers no reason to expect non-disclosed PLHIV to differ from people living without HIV in these network structural forms.

\section{Summary of Current Study}

This paper considers both the stigma and network activation perspective in the empirical context of HIV/AIDS among South Africans aged 40+. South Africa is arguably the epicenter of a global aging HIV/AIDS epidemic, containing an estimated 1.2 million PLHIV aged 50+ in 2017 [37]. Using data from a large community sample in Agincourt, South Africa, this study examines network functionality (regular access to social support) as well as three structural aspects (network size, kin/non-kin composition, and bridging potential) to provide a wholistic portrait of how stigma and activation may operate in varied-perhaps co-occurring-ways depending on outcome. Table 1 summarizes the empirical expectations contained in Hypotheses 1-4. Shaded cells show where the disclosure process disambiguates activation expectations from stigma expectations. Taken together, the full set of hypotheses indicate that the personal networks of those living with HIV may exemplify a complex portrait of theoretical patterns.
Table 1 Summary of empirical expectations

\begin{tabular}{|l|c|c|}
\hline $\begin{array}{l}\text { PLHIV compared to people without } \\
\text { HIV }\end{array}$ & Stigma & Activation \\
\hline Competing hypotheses & & \\
\hline Less availability of support & $\mathrm{X}$ & \\
\hline More availability of support & & $\mathrm{X}$ \\
\hline Smaller core networks & & $\mathrm{X}$ \\
\hline Larger core networks & & \\
\hline & & \\
\hline Compatible hypotheses & & \\
\hline Higher non-kin composition & $\mathrm{X}$ & \\
\hline Undisclosed & $\mathrm{X}$ & $\mathrm{X}$ \\
\hline Disclosed & & \\
\hline & & \\
\hline Higher bridging potential & $\mathrm{X}$ & \\
\hline Undisclosed & $\mathrm{X}$ & $\mathrm{X}$ \\
\hline Disclosed & & \\
\hline
\end{tabular}

Shaded cells show where the disclosure process helps differentiate network activation expectations from stigma expectations. When HIV is disclosed, both perspectives converge on identical prediction. But when HIV is not disclosed (shaded cells), only stigma theory anticipates differences from those without HIV

\section{Methods}

\section{Sample}

We test our hypotheses with data from a global health surveillance system, the International Network for the Demographic Evaluation of Populations and Their Health (INDEPTH). Researchers affiliated with this network launched Health and Aging in Africa: A Longitudinal Study of an INDEPTH Community in South Africa (HAALSI) in 2014. HAALSI is a population-based cohort study set in rural South Africa designed to study health, aging, and well-being.

The sample is derived from 27 villages located in the MRC/Wits Agincourt Rural Public Health and Health Transitions Research Unit site in Mpumalanga Province, South Africa. This district is similar to much of rural South Africa in several respects, including an underdeveloped education system, limited employment opportunity, insufficient healthcare and sanitation, high rates of labor migration, and a recent improvement to life expectancy since the introduction of antiretroviral treatment to supress HIV/AIDS in 2007 [38].

Eligible HAALSI participants were required to be 40 or older as of July 1, 2014 and must have lived in the study site for the year prior to the 2013 local census. A random sample of eligible men and women was obtained with an $87 \%$ response rate $(n=5059)$. Additional details about sampling procedure and ethics approval is described in Gómez-Olivé et al. [39] and Harling et al. [40].

HAALSI survey data follow measurement strategies from well-established studies of aging, including the Health and Retirement Study and the National Social Life, Health and 
Aging Project (NSHAP). Social network measures (discussed below) were adapted from the latter study's specialized network module. Network questions were asked during the structured in-home interview, which was conducted by local survey staff in the xiTsonga language.

The analytic sample for this study differs depending on outcome. All 5059 respondents have valid scores for social network size and availability of emotional support. For proportion network that is non-kin, only respondents with at least one network member are eligible for analysis. This restricts the sample to 4807 individuals (i.e., 252 people reporting having no one in their network). Bridging potential requires a network size of least two, and so this further restricts our sample to 4231 for selected analyses.

\section{Measures}

\section{Dependent Variables}

Network members (alters) were enumerated through a name generator, the standard technique for measuring personal (egocentric) networks in social surveys [41]. In brief, "egocentric network data focus on the network surrounding one node, known as the ego. Data are on nodes that share the chosen relation(s) with the ego and on relations between those nodes" [42]. Respondents were first given the following prompt: "Please tell me the names of 6 adults with whom you have been in communication either in person or by phone or by internet in the past 6 months, starting with the person who is most important to you for any reason." For a comparison to the questions initiated by the NSAHP, see [43]. Respondents were free to list fewer than six names, and spouses were then auto-filled as an additional network member if not initially included among the alters. As with NSAHP, once the network was established, respondents were asked a series of follow-up questions about the members. This information includes the frequency with which each network member provides emotional support, the role relationship of alter to ego, and the frequency with which the alter is believed to communicate with each other alter.

Based on questions from this network module, we created four outcome variables. Network size is the simple sum of all identified network members. Availability of emotional support is a dichotomous variable denoting whether the respondent has any network member who has been

\footnotetext{
1 The complete set of response options for emotional support includes "every day or almost every day", "a few times per week", "once per week", "a few times in the past 6 months", and "not at all." Dichotomizing availability of emotional support at more stringent cut-points (e.g., "once per week") lowers the overall prevalence of the variable but does not affect conclusions when comparing PLHIV to people living without HIV.
}

emotionally supportive at least "a few times in the past 6 months" $(0=$ any and all network members have done so "not at all"). ${ }^{1}$ To determine proportion non-kin in network, we identify which network members are described as something other than marital partners, children, or other relatives, take the sum, and divide by overall network size. Our measure of network bridging potential conveys whether respondents have at least one pair of network alters believed to not have spoken together in the past 6 months and who are not connected indirectly via other network members. ${ }^{2}$ This is a binary indicator of whether the focal individual "serves as the sole intermediary" (pg. 137) between any of his or her close contacts [44].

\section{Independent Variable}

HAALSI respondents were asked a series of questions about HIV. We identified people as living with the condition if they indicated ever having "tested positive for HIV" $(1=$ yes, $0=$ no). Respondents who did not know or refused to answer were counted as missing. Selected analyses further differentiate PLHIV who have disclosed their condition from those who have not. This information was obtained from a survey question in which the respondent was asked "have you ever informed anyone about your HIV status" ( $1=$ yes, $0=$ no). Analyses assessing disclosure therefore incorporate a threecategory variable: $0=$ non-HIV,$+ 1=\mathrm{HIV}+$ disclosed, and $2=\mathrm{HIV}+$ non-disclosed.

\section{Covariates}

Many factors characterizing the population of PLHIV may associate with South Africans' social network characteristics. Our analysis therefore controls for numerous demographic and health variables to minimize spurious differences from the PLHIV and others. Age is coded categorically in decade sets $(40-49,50-59,60-69,70-79,80+)$ and gender and partnership status are both dichotomous covariates. ${ }^{3}$ Educational levels are coded as categories based on years of formal schooling (no education, 1-7 years, 8-11 years, $12+$ years). We used the household asset index, as provided by the HAALSI team, to account for wealth. The index is based on a principal components analysis, which weighted 42 household variables based on consumer durables (e.g.,

\footnotetext{
${ }^{2}$ When reporting whether network alters knew one another, respondents could select "every day or almost every day", "a few times per week", "once per week", a few times per month", "once per month, "a few times in the past 6 months", or "not at all". Bridging potential implies disconnected alters, which is why we dichotomized "not at all" from all other response options.

${ }^{3}$ Age categories were used to examine potential non-linear age patterns. Results were consistent when age was coded in years.
} 
number of cars, computers, electric fans), livestock (e.g., number of cows), and housing characteristics (e.g., brick wall material, toilet location) (see [45] for further details). In a separate section of the survey, respondents were asked for their household size; given the large right skew we re-coded this lives alone (reference), lives with one other person, living in a 3-6 person household, and living in a 7+ person household [46]. We further control for number of living children which is coded as a count variable, top-coded at 10 children. General health is measured with two variables. The first is self-rated physical health, which includes the categories of very good, good, moderate, bad, and very bad health (reference). The second health variable captures physical functioning, and is a count of difficulties people report with the activities of daily life (ADLs): bathing, getting in or out of bed, dressing, eating, using the toilet, and walking across a room (each ADL measured as $0=$ no difficulty, $1=$ difficulty). Finally, we adjust for number of lifetime sexual partners, as this could influence both the likelihood of having HIV and the form and composition of people's networks. Following previous research using HAALSI [47], we coded this as a three-category variable: 0 or 1 lifetime sexual partner (reference), 2-4 sexual partners, and 5 or more lifetime sexual partners.

\section{Analysis}

Our analysis first describes how dependent variables and covariates are distributed differently between those who report being HIV+ and those who report not having HIV. Second, we focus on the subsample of PLHIV respondents and examine potential covariate differences between those who have disclosed and those who have not disclosed their condition to anyone.

Multivariable regression analyses test the hypotheses derived from stigma and activation theories while adjusting for covariates. Models 1 and 2 assess competing hypotheses. Poisson estimation was used for network size, as the dependent variable is a count. The variable's standard deviation is less than its mean, and tests showed no evidence of superior model fit from a negative binomial regression. Access to emotional support from network, a binary variable, uses binomial logistic regression.

Models 3 and 4 examine proportion network that is nonkin and network bridging potential, respectively. As indicated in Table 1, disclosure status is what helps distinguish expectations from each theory; hence, after estimating an initial model which treats PLHIV as a homogenous group, we provide estimates comparing both disclosing PLHIV and non-disclosing PLHIV to those living without HIV. Proportion non-kin is a continuous variable. The variable displayed a negative skew $($ mean $=.21 ; \mathrm{SD}=.31$; skewness $=0.71)$, but residual plots did not indicate violations of ordinary least squares regression assumptions. Hence, we follow the precedent of earlier egocentric analyses and estimate proportion kin with linear regression [48, 49]. Bridging potential is dichotomous, so we use binomial logistic regression.

Missing data is minimal, as less than 2 percent of cases on all covariates were missing. All regression analyses use data multiply imputed by chained equations (MICE) [50] $(m=20)$. We included our dependent variables in the imputation models, but then excluded cases missing on the dependent variable from all analyses [51]. Results were consistent whether using listwise deletion or multiple imputation.

\section{Results}

\section{Descriptive Patterns}

General characteristics of the HAALSI sample have been previously reported [39], so we focus our descriptive analysis on the variables most pertinent to the current study. Briefly, however, just over half are between the ages of 50 and 69 (54\%), with $18 \%$ in their $40 \mathrm{~s}$ and $28 \% 70$ and older. About half of the sample is currently partnered, and $54 \%$ are women. As indicated in Table 2, HAALSI respondents recount an average of just over three close network members. Over $80 \%$ respondents had access to support from their network connections, while one in five of such members came from outside the family, on average. Network bridging potential was evidenced by $12 \%$ of the overall sample (among those listing two or more ties). Table 2 also indicates statistically significant mean or proportion differences according to HIV status for three of the four network measures. Though such comparisons are provisional because they lack adjustment for key covariates, we observe that PLHIV have .12 more ties than others $(p=.04)$. Their networks are also more bridgeable and more likely to be populated by non-kin alters $(p=.001)$.

About $12 \%$ of the HAALSI sample indicated that they had HIV, 75\% of whom reported having disclosed their HIV status. PLHIV differed from their peers on a number of traits. They were less likely to be currently partnered $(p=.000)$, yet reported more lifetime sexual partners $(p=.000)$. They were also less likely to live in large households $(p=.04)$ or to be concentrated in the oldest age categories $(p=.000)$. PLHIV tended to have lower household assets than those not living with $\operatorname{HIV}(p=.000)$. There were no discernable health or gender differences by HIV status.

Table 3 considers whether, among those living with HIV, certain traits predicted disclosure. There were no statistically significant differences between disclosing 
Table 2 Descriptive statistics HAALSI study (HIV+ vs. Non-HIV+)

\begin{tabular}{|c|c|c|c|c|c|c|c|c|c|}
\hline & \multicolumn{3}{|c|}{ Total sample $(\mathrm{N}=5059)$} & \multicolumn{2}{|c|}{$\mathrm{HIV}+(\mathrm{N}=623)$} & \multicolumn{2}{|l|}{$\begin{array}{l}\text { Non-HIV+ } \\
(\mathrm{N}=4436)\end{array}$} & \multicolumn{2}{|c|}{ Difference Test } \\
\hline & Range & $\mathrm{N}(\%)$, Mean & SD & $\mathrm{N}(\%)$, Mean & SD & $\mathrm{N}(\%)$, Mean & SD & $|t| \chi^{2}$ & ( $\mathrm{p}$ value) \\
\hline Network size $(n=5059)$ & $0-7$ & 3.07 & 1.69 & 3.18 & 1.69 & 3.06 & 1.69 & 1.65 & $p=.04$ \\
\hline Emotional support $(n=5059)$ & & $4300(85 \%)$ & & $542(87 \%)$ & & $3771(85 \%)$ & & 1.67 & $p=.20$ \\
\hline Proportion non-kin in network $(n=4807)$ & $0-1$ & 0.21 & 0.31 & 0.24 & 0.33 & 0.20 & 0.31 & 2.79 & $p=.001$ \\
\hline Network bridging potential $(n=4231)$ & & $592(14 \%)$ & & $106(17 \%)$ & & $577(13 \%)$ & & 10.11 & $p=.001$ \\
\hline \multicolumn{10}{|l|}{ HIV status } \\
\hline No HIV & & $4436(89 \%)$ & & & & & & & \\
\hline HIV & & $623(11 \%)$ & & & & & & & \\
\hline Female & & $2732(54 \%)$ & & $336(54 \%)$ & & $2395(54 \%)$ & & .01 & $p=.94$ \\
\hline Partnered & & $2581(51 \%)$ & & $249(40 \%)$ & & $2351(53 \%)$ & & 35.56 & $p=.000$ \\
\hline Number of lifetime sexual partners & & & & & & & & 76.15 & $p=.000$ \\
\hline $0-1$ & & $1467(29 \%)$ & & $93(15 \%)$ & & $1375(31 \%)$ & & & \\
\hline $2-4$ & & $1720(34 \%)$ & & $231(37 \%)$ & & $1508(34 \%)$ & & & \\
\hline 5 or more & & $1872(37 \%)$ & & $29,948 \%$ & & $1553(35 \%)$ & & & \\
\hline Age group & & & & & & & & 192.45 & $p=.000$ \\
\hline 40-49 Years & & $911(18 \%)$ & & $174(28 \%)$ & & $737(17 \%)$ & & & \\
\hline 50-59 Years & & $1417(28 \%)$ & & $255(41 \%)$ & & $1153(26 \%)$ & & & \\
\hline 60-69 Years & & $1315(26 \%)$ & & $143(23 \%)$ & & $1152(26 \%)$ & & & \\
\hline 70-79 Years & & $860(17 \%)$ & & $50(8 \%)$ & & $843(19 \%)$ & & & \\
\hline $80+$ Years & & $556(11 \%)$ & & $6(1 \%)$ & & $531(12 \%)$ & & & \\
\hline Education & & & & & & & & 23.42 & $p=.000$ \\
\hline No formal education & & $2327(46 \%)$ & & $237(38 \%)$ & & $2085(47 \%)$ & & & \\
\hline Some primary (1-7 years) & & $1720(34 \%)$ & & $231(37 \%)$ & & $1508(34 \%)$ & & & \\
\hline Some secondary ( $8-11$ years) & & $557(11 \%)$ & & $100(16 \%)$ & & $489(11 \%)$ & & & \\
\hline Secondary or more $(12+$ years $)$ & & $455(9 \%)$ & & $55(9 \%)$ & & $354(8 \%)$ & & & \\
\hline Household assets index & -4.53 to 11.2 & 0.03 & 2.36 & -0.32 & 2.12 & 0.07 & 2.40 & 3.85 & $p=.000$ \\
\hline Household size & & & & & & & & 8.34 & $p=.04$ \\
\hline Lives alone & & $556(11 \%)$ & & $81(13 \%)$ & & $443(10 \%)$ & & & \\
\hline Lives with one other person & & $556(11 \%)$ & & $69(11 \%)$ & & $489(11 \%)$ & & & \\
\hline Living in $3-6$ person household & & $2428(48 \%)$ & & $318(51 \%)$ & & $2129(48 \%)$ & & & \\
\hline Living in $7+$ person household & & $1569(31 \%)$ & & $155(25 \%)$ & & $1375(31 \%)$ & & & \\
\hline Number of children & $0-10$ & 4.45 & 2.55 & 4.30 & 2.44 & 4.48 & 2.57 & 1.55 & $p=.12$ \\
\hline Self-rated health & & & & & & & & 3.44 & $p=.49$ \\
\hline Very bad & & $101(2 \%)$ & & $12(2 \%)$ & & $89(2 \%)$ & & & \\
\hline $\mathrm{Bad}$ & & $860(17 \%)$ & & $93(15 \%)$ & & $754(17 \%)$ & & & \\
\hline Moderate & & $658(13 \%)$ & & $75(12 \%)$ & & $577(13 \%)$ & & & \\
\hline Good & & $2428(48 \%)$ & & $312(50 \%)$ & & $2129(48 \%)$ & & & \\
\hline Very good & & $1012(20 \%)$ & & $131(21 \%)$ & & $887(20 \%)$ & & & \\
\hline Functional limitations (count of ADLs) & $0-6$ & 0.22 & 0.88 & 0.21 & 0.87 & 0.22 & 0.86 & 0.47 & $p=.64$ \\
\hline
\end{tabular}

Standard deviations omitted for categorical variables

and non-disclosing PLHIV across the full set of covariates considered in this study.

\section{Multivariable Regression}

We present the results of hypothesis tests in Table 4. Columns 1 and 2 assess the competing expectations derived from the stigma and activation perspectives. The incident rate ratio in Column 1 indicates that relative to those without HIV, living with HIV increases the count of network members by $8 \%(\mathrm{IRR}=1.08,95 \%$ CI $1.03,1.13, p=.000)$. To enhance interpretability, we present predicted count values based on this model in Fig. 2. Panel A indicates that PLHIV have, on average, nearly $1 / 4$ additional network members 
Table 3 Descriptive statistics, HAASLI study (non-disclosing PLHIV vs. disclosing PLHIV)

\begin{tabular}{|c|c|c|c|c|c|c|}
\hline & $\begin{array}{l}\text { HIV+ non-disclosed } \\
(\mathrm{N}=144) \mathrm{N}(\%), \text { mean }\end{array}$ & SD & $\begin{array}{l}\mathrm{HIV}+\text { disclosed } \\
(\mathrm{N}=432) \mathrm{N}(\%) \text {, mean }\end{array}$ & SD & $|t| / \chi^{2}$ & $\begin{array}{l}\text { Difference } \\
\text { test (p } \\
\text { value) }\end{array}$ \\
\hline Female & $73(51 \%)$ & & $242(56 \%)$ & & 1.03 & $p=.31$ \\
\hline Partnered & $48(33 \%)$ & & $177(41 \%)$ & & 2.34 & $p=.12$ \\
\hline Number of lifetime sexual partners & & & & & 2.17 & $p=.34$ \\
\hline $0-1$ & $19(13 \%)$ & & $82(19 \%)$ & & & \\
\hline $2-4$ & $53(37 \%)$ & & $160(37 \%)$ & & & \\
\hline 5 or more & $72(50 \%)$ & & $190(44 \%)$ & & & \\
\hline Age group & & & & & 0.29 & $p=.99$ \\
\hline 40-49 Years & $42(29 \%)$ & & $116(27 \%)$ & & & \\
\hline 50-59 Years & $60(42 \%)$ & & $181(42 \%)$ & & & \\
\hline 60-69 Years & $30(21 \%)$ & & $95(22 \%)$ & & & \\
\hline 70-79 Years & $10(7 \%)$ & & $35(8 \%)$ & & & \\
\hline $80+$ Years & $2(1 \%)$ & & $5(1 \%)$ & & & \\
\hline Education & & & & & 3.61 & $p=.31$ \\
\hline No formal education & $55(38 \%)$ & & $160(37 \%)$ & & & \\
\hline Some primary ( $1-7$ years) & $48(33 \%)$ & & $177(41 \%)$ & & & \\
\hline Some secondary ( $8-11$ years) & $26(18 \%)$ & & $65(15 \%)$ & & & \\
\hline Secondary or more $(12+$ years $)$ & $16(11 \%)$ & & $30(7 \%)$ & & & \\
\hline Household assets index & -0.20 & 2.08 & -0.34 & 2.15 & 0.69 & $p=.49$ \\
\hline Household size & & & & & 1.06 & $p=.79$ \\
\hline Lives alone & $(14 \%)$ & & $52(12 \%)$ & & & \\
\hline Lives with one other person & $(11 \%)$ & & $43(10 \%)$ & & & \\
\hline Living in $3-6$ person household & $(52 \%)$ & & $220(51 \%)$ & & & \\
\hline Living in $7+$ person household & $(23 \%)$ & & $116(27 \%)$ & & & \\
\hline Number of children & 4.41 & 2.34 & 4.31 & 2.40 & 0.42 & $p=.68$ \\
\hline Self-rated health & & & & & 8.46 & $p=.08$ \\
\hline Very bad & $(1 \%)$ & & $4(1 \%)$ & & & \\
\hline $\mathrm{Bad}$ & $(17 \%)$ & & $65(15 \%)$ & & & \\
\hline Moderate & $(13 \%)$ & & $52(12 \%)$ & & & \\
\hline Good & $(56 \%)$ & & $207(48 \%)$ & & & \\
\hline Very good & $(15 \%)$ & & $104(24 \%)$ & & & \\
\hline Functional limitations (count of ADLs) & 0.14 & 0.57 & 0.21 & 0.89 & 0.82 & $p=.41$ \\
\hline
\end{tabular}

Standard deviations omitted for categorical variables

(3.21 vs. 2.98). The second column of Table 4 , however, suggests that living with HIV means neither surplus nor absence of emotional support (OR 1.21, 95\% CI 0.93, 1.58, $p=.15)$. This is confirmed by the predicted probability values in Panel B of Fig. 2: PLHIV and those without HIV alike have a $90 \%$ likelihood of reporting regular access to emotional support from network members.

Moving to the third and fourth outcomes in the right half of Table 4, regression models reveal that when homogenized, PLHIV are not statistically distinct from other participants on both outcomes (models a). However, the linear regression coefficient and the logistic regression odds ratio comparing the non-disclosing PLHIV to those without HIV (models b) are both statistically significant, net of covariates $(B=0.08,95 \%$ CI $0.02,0.13, p=.004$ for proportion of non-kin, and OR 2.11, 95\% CI 1.33, 3.34, $p=.002$ for network bridging potential). Coefficients for disclosing PLHIV, on the other hand, are insufficient to reject the null hypothesis $(B=-0.02,95 \%$ CI -0.05 , $0.01, p=.22$ for proportion of non-kin, and OR $1.03,95 \%$ CI $0.75,1.41, p=.86$ for network bridging potential).

As shown in Fig. 2, Panel C, disclosing PLHIV are statistically indistinguishable from those without HIV, with both groups averaging about 1 in 5 network members from outside their family. PLHIV who have not disclosed their condition, however, average nearly .30 for non-kin network composition. We observe a similar pattern for network bridging potential, where only the non-disclosing PLHIV 
Table 4 Estimates from regression models predicting network outcomes

\begin{tabular}{|c|c|c|c|c|c|c|}
\hline & \multirow{3}{*}{ 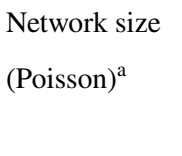 } & \multirow{3}{*}{$\begin{array}{l}\text { Emotional support } \\
\text { (Logit) }^{\mathrm{b}}\end{array}$} & \multicolumn{2}{|c|}{ Proportion of non-kin in network } & \multicolumn{2}{|c|}{ Network bridging potential } \\
\hline & & & \multicolumn{2}{|l|}{$(\mathrm{OLS})^{\mathrm{c}}$} & \multicolumn{2}{|l|}{$(\text { Logit })^{b}$} \\
\hline & & & Model a & Model b & Model a & Model b \\
\hline $\mathrm{HIV}+{ }^{\mathrm{d}}$ & $\begin{array}{l}1.08 \\
\text { (1.03 to } 1.13)\end{array}$ & $\begin{array}{l}1.21 \\
(0.93 \text { to } 1.58)\end{array}$ & $\begin{array}{l}0.01 \\
(-0.02 \text { to } 0.03)\end{array}$ & & $\begin{array}{l}1.25 \\
(0.96 \text { to } 1.63)\end{array}$ & \\
\hline \multicolumn{7}{|l|}{ HIV disclosure status } \\
\hline $\mathrm{HIV}+$ non-disclosed $^{\mathrm{d}}$ & & & & $\begin{array}{l}0.08 \\
(0.02 \text { to } 0.13)\end{array}$ & & $\begin{array}{l}2.11 \\
\text { (1.33 to } 3.34)\end{array}$ \\
\hline HIV+-disclosed ${ }^{\mathrm{d}}$ & & & & $\begin{array}{l}-0.02 \\
(-0.05 \text { to } 0.01)\end{array}$ & & $\begin{array}{l}1.03 \\
(0.75 \text { to } 1.41)\end{array}$ \\
\hline Female & $\begin{array}{l}1.13 \\
(1.08 \text { to } 1.18)\end{array}$ & $\begin{array}{l}0.91 \\
(0.74 \text { to } 1.12)\end{array}$ & $\begin{array}{l}-0.04 \\
(-0.06 \text { to }-0.01)\end{array}$ & $\begin{array}{l}-0.03 \\
(-0.06 \text { to }-0.01)\end{array}$ & $\begin{array}{l}0.83 \\
(0.65 \text { to } 1.06)\end{array}$ & $\begin{array}{l}0.84 \\
(0.66 \text { to } 1.08)\end{array}$ \\
\hline Partnered & $\begin{array}{l}1.38 \\
(1.33 \text { to } 1.43)\end{array}$ & $\begin{array}{l}2.12 \\
\text { (1.71 to } 2.62)\end{array}$ & $\begin{array}{l}-0.08 \\
(-.0 .10 \text { to }-0.06)\end{array}$ & $\begin{array}{l}-0.08 \\
(-0.10 \text { to }-0.05)\end{array}$ & $\begin{array}{l}0.91 \\
(0.72 \text { to } 1.13)\end{array}$ & $\begin{array}{l}0.91 \\
(0.73 \text { to } 1.14)\end{array}$ \\
\hline \multicolumn{7}{|c|}{ Number of lifetime sexual partners } \\
\hline $2-4^{e}$ & $\begin{array}{l}1.03 \\
(0.99 \text { to } 1.08)\end{array}$ & $\begin{array}{l}1.19 \\
(0.96 \text { to } 1.49)\end{array}$ & $\begin{array}{l}0.05 \\
(0.02 \text { to } 0.07)\end{array}$ & $\begin{array}{l}0.05 \\
(0.02 \text { to } 0.07)\end{array}$ & $\begin{array}{l}1.06 \\
(0.83 \text { to } 1.36)\end{array}$ & $\begin{array}{l}1.07 \\
(0.84 \text { to } 1.37)\end{array}$ \\
\hline 5 or more ${ }^{e}$ & $\begin{array}{l}1.09 \\
(1.04 \text { to } 1.14)\end{array}$ & $\begin{array}{l}0.70 \\
(0.55 \text { to } 0.89)\end{array}$ & $\begin{array}{l}0.04 \\
(0.02 \text { to } 0.07)\end{array}$ & $\begin{array}{l}0.05 \\
(0.02 \text { to } 0.07)\end{array}$ & $\begin{array}{l}0.85 \\
(0.64 \text { to } 1.14)\end{array}$ & $\begin{array}{l}0.86 \\
(0.64 \text { to } 1.15)\end{array}$ \\
\hline \multicolumn{7}{|l|}{ Age group } \\
\hline $50-59$ Years $^{\mathrm{f}}$ & $\begin{array}{l}1.02 \\
(0.97 \text { to } 1.07)\end{array}$ & $\begin{array}{l}1.23 \\
(0.94 \text { to } 1.60)\end{array}$ & $\begin{array}{l}-0.02 \\
(-0.05 \text { to } 0.01)\end{array}$ & $\begin{array}{l}-0.02 \\
(-0.05 \text { to } 0.01)\end{array}$ & $\begin{array}{l}0.79 \\
(0.61 \text { to } .1 .04)\end{array}$ & $\begin{array}{l}0.80 \\
(0.61 \text { to } 1.04)\end{array}$ \\
\hline $60-69$ Years $^{\mathrm{f}}$ & $\begin{array}{l}1.06 \\
(1.00 \text { to } 1.12)\end{array}$ & $\begin{array}{l}1.09 \\
\text { (0.82 to } 1.45)\end{array}$ & $\begin{array}{l}-0.04 \\
(-0.07 \text { to }-0.01)\end{array}$ & $\begin{array}{l}-0.04 \\
(-0.07 \text { to }-0.01)\end{array}$ & $\begin{array}{l}0.67 \\
(0.49 \text { to } 0.90)\end{array}$ & $\begin{array}{l}0.67 \\
(0.50 \text { to } 0.91)\end{array}$ \\
\hline 70-79 Years $^{\mathrm{f}}$ & $\begin{array}{l}1.04 \\
(0.98 \text { to } 1.10)\end{array}$ & $\begin{array}{l}0.87 \\
(0.64 \text { to } 1.17)\end{array}$ & $\begin{array}{l}-0.06 \\
(-0.09 \text { to }-0.03)\end{array}$ & $\begin{array}{l}-0.07 \\
(-0.10 \text { to }-0.03)\end{array}$ & $\begin{array}{l}0.45 \\
(0.31 \text { to } 0.66)\end{array}$ & $\begin{array}{l}0.46 \\
(0.32 \text { to } 0.67)\end{array}$ \\
\hline $80+$ Years $^{\mathrm{f}}$ & $\begin{array}{l}1.03 \\
(0.95 \text { to } 1.10)\end{array}$ & $\begin{array}{l}1.04 \\
(0.73 \text { to } 1.48)\end{array}$ & $\begin{array}{l}-0.10 \\
(-0.14 \text { to }-0.06)\end{array}$ & $\begin{array}{l}-0.10 \\
(-0.14 \text { to }-0.06)\end{array}$ & $\begin{array}{l}0.60 \\
(0.39 \text { to } 0.92)\end{array}$ & $\begin{array}{l}0.61 \\
(0.40 \text { to } 0.93)\end{array}$ \\
\hline \multicolumn{7}{|l|}{ Education } \\
\hline Some primary ${ }^{\mathrm{g}}$ & $\begin{array}{l}1.05 \\
(1.01 \text { to } 1.09)\end{array}$ & $\begin{array}{l}1.12 \\
(0.92 \text { to } 1.37)\end{array}$ & $\begin{array}{l}-0.01 \\
(-0.02 \text { to } 0.01)\end{array}$ & $\begin{array}{l}-0.01 \\
(-0.03 \text { to } 0.01)\end{array}$ & $\begin{array}{l}1.08 \\
(0.86 \text { to } 1.35)\end{array}$ & $\begin{array}{l}1.09 \\
(0.87 \text { to } 1.36)\end{array}$ \\
\hline Some secondary ${ }^{\mathrm{g}}$ & $\begin{array}{l}1.05 \\
(1.00 \text { to } 1.11)\end{array}$ & $\begin{array}{l}1.16 \\
(0.85 \text { to } 1.58)\end{array}$ & $\begin{array}{l}-0.01 \\
(-0.03 \text { to } 0.03)\end{array}$ & $\begin{array}{l}-0.002 \\
(-0.03 \text { to } 0.03)\end{array}$ & $\begin{array}{l}1.28 \\
(0.93 \text { to } 1.76)\end{array}$ & $\begin{array}{l}1.27 \\
(0.92 \text { to } 1.75)\end{array}$ \\
\hline Secondary or more ${ }^{\mathrm{g}}$ & $\begin{array}{l}1.01 \\
(0.94 \text { to } 1.09)\end{array}$ & $\begin{array}{l}1.28 \\
(0.88 \text { to } 1.86)\end{array}$ & $\begin{array}{l}-0.01 \\
(-0.05 \text { to } 0.03)\end{array}$ & $\begin{array}{l}-0.01 \\
(-0.03 \text { to } 0.03)\end{array}$ & $\begin{array}{l}1.18 \\
(0.80 \text { to } 1.74)\end{array}$ & $\begin{array}{l}1.18 \\
(0.80 \text { to } 1.74)\end{array}$ \\
\hline Household assets index & $\begin{array}{l}1.01 \\
(1.00 \text { to } 1.01)\end{array}$ & $\begin{array}{l}0.96 \\
(0.92 \text { to } 1.00)\end{array}$ & $\begin{array}{l}-0.001 \\
(-0.01 \text { to } 0.01)\end{array}$ & $\begin{array}{l}-0.001 \\
(-0.01 \text { to } 0.01)\end{array}$ & $\begin{array}{l}1.00 \\
(0.95 \text { to } 1.04)\end{array}$ & $\begin{array}{l}0.99 \\
(0.95 \text { to } 1.04)\end{array}$ \\
\hline \multicolumn{7}{|l|}{ Household size } \\
\hline Living with one other person ${ }^{\mathrm{h}}$ & $\begin{array}{l}1.07 \\
(0.99 \text { to } 1.15)\end{array}$ & $\begin{array}{l}1.30 \\
(0.94 \text { to } 1.79)\end{array}$ & $\begin{array}{l}-0.04 \\
(-0.08 \text { to }-0.01)\end{array}$ & $\begin{array}{l}-0.04 \\
(-0.08 \text { to to } 0.01)\end{array}$ & $\begin{array}{l}0.60 \\
(0.38 \text { to } 0.93)\end{array}$ & $\begin{array}{l}0.61 \\
(0.39 \text { to } 0.94)\end{array}$ \\
\hline $\begin{array}{l}\text { Living in 3-6 person } \\
\text { household }^{\mathrm{h}}\end{array}$ & $\begin{array}{l}1.05 \\
(0.99 \text { to } 1.12)\end{array}$ & $\begin{array}{l}1.43 \\
(1.10 \text { to } 1.84)\end{array}$ & $\begin{array}{l}-0.01 \\
(-0.04 \text { to } 0.02)\end{array}$ & $\begin{array}{l}-0.01 \\
(-0.04 \text { to } 0.02)\end{array}$ & $\begin{array}{l}0.74 \\
(0.52 \text { to } 1.05)\end{array}$ & $\begin{array}{l}0.75 \\
(0.53 \text { to } 1.06)\end{array}$ \\
\hline $\begin{array}{l}\text { Living in } 7+\text { person } \\
\text { household }^{\mathrm{h}}\end{array}$ & $\begin{array}{l}1.05 \\
(0.98 \text { to } 1.13)\end{array}$ & $\begin{array}{l}1.53 \\
(1.14 \text { to } 2.05)\end{array}$ & $\begin{array}{l}-0.01 \\
(-0.05 \text { to } 0.02)\end{array}$ & $\begin{array}{l}-0.01 \\
(-0.05 \text { to } 0.02)\end{array}$ & $\begin{array}{l}0.72 \\
(0.49 \text { to } 1.06)\end{array}$ & $\begin{array}{l}0.73 \\
(0.50 \text { to } 1.07)\end{array}$ \\
\hline Number of children & $\begin{array}{l}1.02 \\
(1.02 \text { to } 1.03)\end{array}$ & $\begin{array}{l}1.03 \\
(0.99 \text { to } 1.06)\end{array}$ & $\begin{array}{l}-0.002 \\
(-0.01 \text { to } 0.01)\end{array}$ & $\begin{array}{l}-0.002 \\
(-0.01 \text { to } 0.01)\end{array}$ & $\begin{array}{l}0.97 \\
(0.94 \text { to } 1.02)\end{array}$ & $\begin{array}{l}0.97 \\
(0.93 \text { to } 1.02)\end{array}$ \\
\hline \multicolumn{7}{|l|}{ Self-rated health } \\
\hline $\mathrm{Bad}^{\mathrm{i}}$ & $\begin{array}{l}1.21 \\
(1.05 \text { to } 1.39)\end{array}$ & $\begin{array}{l}1.94 \\
\text { (1.16 to } 3.22)\end{array}$ & $\begin{array}{l}-0.04 \\
(-0.12 \text { to } 0.04)\end{array}$ & $\begin{array}{l}-0.04 \\
(-0.12 \text { to } 0.03)\end{array}$ & $\begin{array}{l}0.65 \\
(0.30 \text { to } 1.40)\end{array}$ & $\begin{array}{l}0.63 \\
(0.29 \text { to } 1.37)\end{array}$ \\
\hline Moderate $^{\mathrm{i}}$ & $\begin{array}{l}1.22 \\
(1.05 \text { to } 1.40)\end{array}$ & $\begin{array}{l}2.20 \\
(1.32 \text { to } 3.84)\end{array}$ & $\begin{array}{l}-0.04 \\
(-0.11 \text { to } 0.04)\end{array}$ & $\begin{array}{l}-0.03 \\
(-0.12 \text { to } 0.04)\end{array}$ & $\begin{array}{l}0.55 \\
(0.25 \text { to } 1.21)\end{array}$ & $\begin{array}{l}0.54 \\
(0.25 \text { to } 1.19)\end{array}$ \\
\hline Good $^{\mathrm{i}}$ & $\begin{array}{l}1.27 \\
(1.09 \text { to } 1.45)\end{array}$ & $\begin{array}{l}1.68 \\
(1.02 \text { to } 2.78)\end{array}$ & $\begin{array}{l}-0.05 \\
(-0.12 \text { to } 0.03)\end{array}$ & $\begin{array}{l}-0.05 \\
(-0.13 \text { to } 0.03)\end{array}$ & $\begin{array}{l}0.55 \\
(0.26 \text { to } 1.17)\end{array}$ & $\begin{array}{l}0.54 \\
(0.25 \text { to } 1.14)\end{array}$ \\
\hline Very good ${ }^{\mathrm{i}}$ & $\begin{array}{l}1.20 \\
(1.05 \text { to } 1.40)\end{array}$ & $\begin{array}{l}1.03 \\
(0.61 \text { to } 1.73)\end{array}$ & $\begin{array}{l}-0.05 \\
(-0.13 \text { to } 0.03)\end{array}$ & $\begin{array}{l}-0.05 \\
(-0.13 \text { to } 0.03)\end{array}$ & $\begin{array}{l}0.71 \\
(0.33 \text { to } 1.53)\end{array}$ & $\begin{array}{l}0.70 \\
(0.32 \text { to } 1.52)\end{array}$ \\
\hline
\end{tabular}


Table 4 (continued)

\begin{tabular}{|c|c|c|c|c|c|c|}
\hline & \multirow{3}{*}{$\begin{array}{l}\text { Network size } \\
\text { (Poisson) }^{\mathrm{a}}\end{array}$} & \multirow{3}{*}{$\begin{array}{l}\text { Emotional support } \\
\text { (Logit) }^{\mathrm{b}}\end{array}$} & \multicolumn{2}{|c|}{ Proportion of non-kin in network } & \multirow{2}{*}{\multicolumn{2}{|c|}{$\frac{\text { Network bridging potential }}{{\text { (Logit })^{\mathrm{b}}}}$}} \\
\hline & & & \multicolumn{2}{|l|}{$(\mathrm{OLS})^{\mathrm{c}}$} & & \\
\hline & & & Model a & Model b & Model a & Model b \\
\hline Functional limitations (ADLs) & $\begin{array}{l}0.90 \\
(0.95 \text { to } 0.99)\end{array}$ & $\begin{array}{l}0.85 \\
(0.77 \text { to } 0.91)\end{array}$ & $\begin{array}{l}-0.01 \\
(-0.03 \text { to }-0.01)\end{array}$ & $\begin{array}{l}-0.02 \\
(-0.03 \text { to }-0.01)\end{array}$ & $\begin{array}{l}0.96 \\
(0.84 \text { to } 1.11)\end{array}$ & $\begin{array}{l}0.97 \\
(0.84 \text { to } 1.11)\end{array}$ \\
\hline $\mathrm{N}$ & 5059 & 5059 & 4807 & 4807 & 4231 & 4231 \\
\hline
\end{tabular}

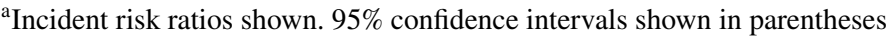

${ }^{b}$ Odds ratios shown. 95\% confidence intervals shown in parentheses. Estimates are adjusted for network size

${ }^{c}$ Unstandardized regression coefficients shown. 95\% confidence intervals shown in parentheses. Estimates are adjusted for network size

${ }^{\mathrm{d}}$ Compared to non-HIV+ individuals

${ }^{\mathrm{e}}$ Compared to $0-1$ lifetime sexual partners

${ }^{\text {f }}$ Compared to $40-49$ years

${ }^{\mathrm{g}}$ Compared to no formal education

${ }^{\mathrm{h}}$ Compared to living alone

${ }^{\mathrm{i}}$ Compared to very bad health
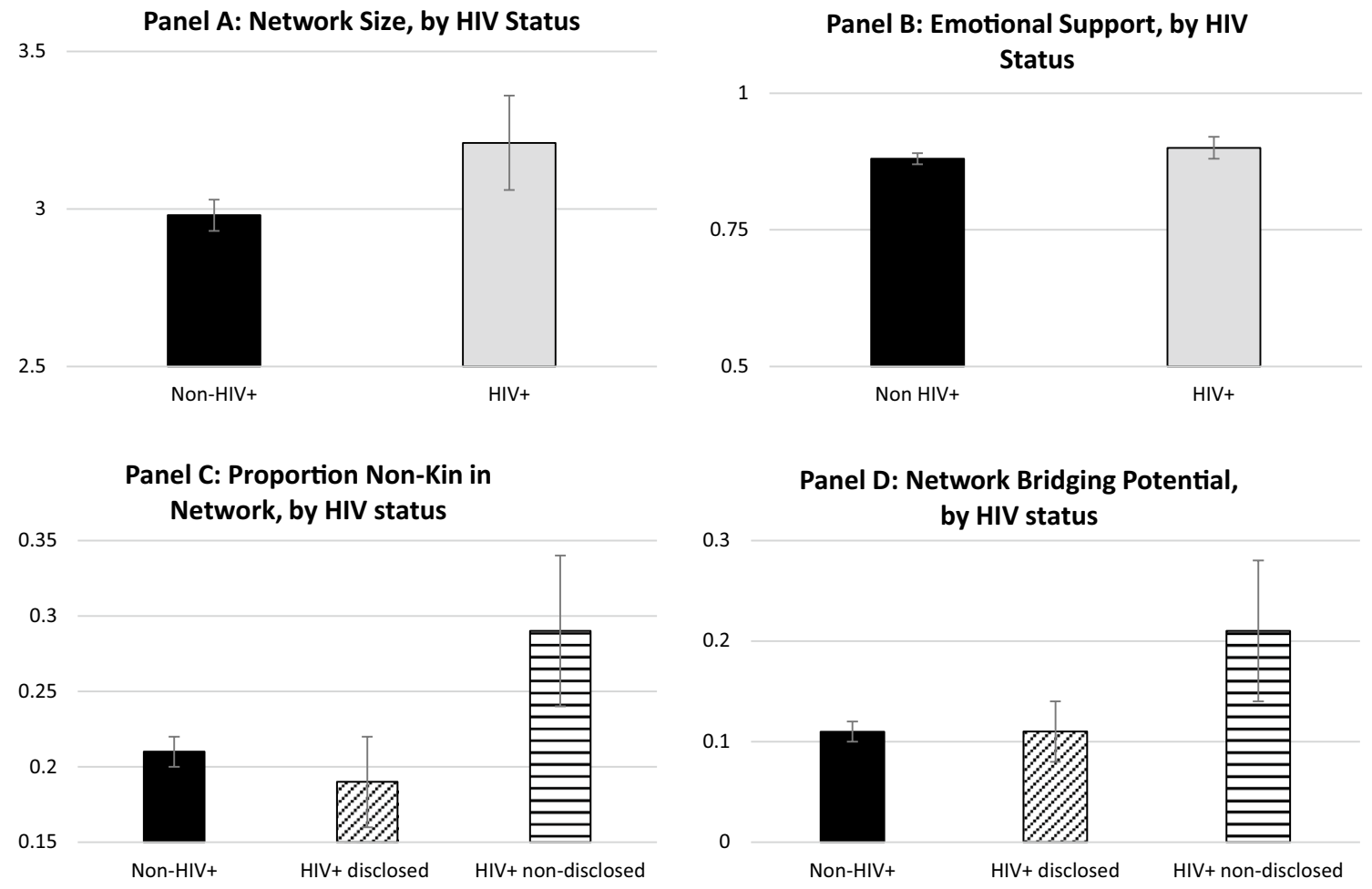

Fig. 2 Predicted probabilities for network outcomes by HIV status. Note Estimates are derived from multivariable regression models in Table 3. All covariates are held at their respective means

differ from those without HIV. As shown in Panel D, only $11 \%$ of those without HIV are estimated to have network bridging potential, approximately half the likelihood that characterizes non-disclosing PLHIV (21\%).
In supplementary analyses, we examined whether the associations shown in Table 4 differed by gender, age, and education. Results of interaction terms did not reveal any evidence that any of these variables 
moderated the associations between HIV status and network characteristics.

\section{Discussion}

Drawing from network activation and stigma perspectives, this study considered whether older PLHIV in South Africa have distinctive personal networks. The overall patterning of evidence-some supporting activation, some hinting at stigma-underscores that the two theoretical perspectives are not necessarily at odds with one another. Even as HIV remains highly stigmatized in many contexts, including the region considered in our study [32], PLHIV appear capable of maintaining networks whose size and supportiveness meet or exceed conditions of the local norm. Yet even while potential sources of support and the ready availability of such resources show no signs of deficit, people most affected by stigma-those who have not disclosed their HIV+ status-inhabit networks characterized by non-kin and by high bridging potential. Such networks may provide a favorable structure to meet the needs of people subjected to stigma.

In line with network activation, PLHIV had more close discussion partners than their non-infected peers in the HAALSI sample. Activation theory specifies that large networks cultivated by people with pressing health needs act as conduits for needed support and ultimately serve as coping mechanisms in dealing with duress [8-11]. Some previous studies have supported the activation perspective, reporting that PLHIV actively establish accommodating relationships with friends [19] and fill gaps in their networks with relatives and neighbors after conflict or estrangement with former ties [19-22]. Other studies, however, have highlighted the commonality of social isolation and rejection from immediate family members, relatives, and friends among PLHIV [17, 52, 53]. Still, the vast majority of such studies feature analyses of small convenience samples drawn from populations of PLHIV. Our results, supporting network activation, extend this existing literature by comparing network size between PLHIV and those not living with HIV.

That said, the theoretical corollary of network sizelikelihood of receiving social support from network ties-did not follow the same trend. The HAALSI sample tended to have high access to at least some emotional aid from their network; we therefore speculate that the high ceiling may have obstructed our ability to detect whether PLHIV are especially supported. In any event, the findings on network size and availability of support rule out the possibility of a network functional deficit. PLHIV's large networks, coupled with high levels of support matching those without HIV, contradict stigma theory and suggest only network activation.

Stigma theory, however, was supported for a subset of PLHIV when it came to compositional and triadic-structural elements of personal networks. Specifically, the 25\% of people who knew they were HIV+ yet did not disclose their condition were far more likely than others to have friends, neighbors, and other non-kin in their core network and to maintain networks of non-overlapping members. Non-kin-centered, bridgeable network forms offer more autonomy and privacy than denser, family-oriented structures [54], and so the fact that non-disclosing PLHIV occupy such relational arrangements implies the endurance of stigma. Indeed, HIV remains stigmatized within many families in the South African context, leading some PLHIV to fear abandonment, rejection, and condemnation from family members [55].We are unaware of any previous studies investigating the structural form of PLHIV in the region, though some studies in Australia [26] and Canada [53] report the importance of non-kin network members. Still, these studies do not offer a comparison between PLHIV and others.

It is important to note that for most PLHIV, stigma did not appear to manifest in people's network form. This is not to assert that those who disclosed their serostatus were immune from discrimination. Yet in the extent to which their network included family vs. non-family members and in their bridging potential, there was no distinguishing the HIV-disclosers from those who did not have the virus.

Results suggest several avenues for future research. For instance, qualitative research could explore non-disclosing PLHIV in more detail. Previous studies report smaller proportions of non-disclosers [31, 56, 57], possibly because most sample from patient populations. Indeed, serostatus non-disclosers are relatively unlikely to get recruited into many studies which recruit only HIV patients, thus presenting a possible form of upward selection bias for estimating disclosure. In any event, more research could inspect how people construct and navigate their networks while living secretly with HIV/AIDS.

Future research can also leverage longitudinal data to investigate processes assumed by our theoretical frameworks and to strengthen causal reasoning. One strategy would be to examine changes in the short-term aftermath of HIV diagnosis. Presumably some portion of the HAALSI sample testing negative for the virus will have received an HIV diagnosis by the follow-up interview (field work currently underway), and so scholars may observe pre- and post- diagnosis network characteristics. Tracking network change over the longer-term can also refine existing frameworks. Foundational studies on activation theory, for instance, find that certain individuals emerge as core network members in the aftermath of a mental health diagnosis, but then often recede 
as people gain competence in managing their condition [7, $58,59]$. We will be able to more thoroughly address these forms of responsive action as future waves of HAALSI are conducted (planned for 2021 and beyond).

These considerations emphasize that the current study is limited in its ability to reach causal conclusions. Given the cross-sectional nature of existing data, for instance, empirical patterns for network form could be interpreted in several ways. One plausible explanation is that people who are wary of disclosing their condition maintain networks that are optimal for safeguarding secrecy. Another account is that experiencing certain network formations shape people's inclination to disclose. Though the present study is unable to resolve this issue, there appears to be an affinity between network structure and disclosure status that resonates with the continuing stigma of HIV/AIDS.

Another limitation is that we lack an exhaustive inventory of respondents' social connections. The name generator tool used to construct networks prompts people to list up to six of their closest ties. People derive support and information from those outside their core network [11] and so such ties are only a subset of all possible meaningful contacts in their lives.

\section{Conclusion}

The present study helps advance the study of HIV/AIDS in sub-Saharan Africa and points to the potential complementarity of two theoretical perspectives related to illness and personal networks. To our knowledge, this is the first study to use a large-scale, community-based probability sample to assess how HIV status is linked to the form and function of older people's core networks. Social networks are key informal mechanisms for sharing information, enhancing mental health, and encouraging compliance with medical treatment, all of which is crucial for people living with HIV. The HIV pandemic will increasingly affect the aging populations of many countries in the global South, and so ongoing efforts to gather and examine data on network outcomes associated with this disease will yield important insights.

Acknowledgements We thank the Editor and blind reviewers for their helpful feedback on earlier versions of this manuscript. This paper was previously presented at the 2019 Gerontological Society of America Annual Meeting in Austin, Texas.

Funding The HAALSI study is funded by the National Institute on Aging from the National Institutes of Health (P01 AG041710), and is nested within the MRC/Wits Rural Public Health and Health Transitions Research Unit (Agincourt), supported by Wellcome Trust (Grants 058893/Z/99/A, 069683/Z/02/Z, 085477/Z/08/Z, and 085477/B/08/Z), the University of the Witwatersrand, and the South African Medical Research Council. Work analyzing these data was supported by the Canadian Social Sciences and Humanities Research Council (Insight
Development Grant \#231615) and from the Ontario Ministry of Research and Innovation Early Researcher Award. The content is solely the responsibility of the authors and does not necessarily represent the official views of the National Institutes of Health or other funding sources.

\section{Compliance with Ethical Standards}

Conflict of interest The authors declare that they have no conflict of interest.

Ethical Approval The University of Toronto Research Ethics Board has provided ethical approval for the analysis of these data.

Informed Consent Study participants provided informed consent, as stipulated the Witwatersrand Human Research Ethics Committee, the Harvard T.H. Chan School of Public Health Office of Human Research Administration, and the Mpumalanga Provincial Research and Ethics Committee.

\section{References}

1. Gallant MP. The influence of social support on chronic illness self-management: a review and directions for research. Health Educ Behav. 2003;30(2):170-95.

2. Sherbourne CD, Hays RD, Ordway L, DiMatteo MR, Kravitz RL. Antecedents of adherence to medical recommendations: results from the medical outcomes study. J Behav Med. 1992;15(5):447-68.

3. Vogt T. Social networks as predictors of ischemic heart disease, cancer, stroke and hypertension: incidence, survival and mortality. J Clin Epidemiol. 1992;45(6):659-66.

4. Gage-Bouchard EA, LaValley S, Panagakis C, Shelton RC. The architecture of support: the activation of preexisting ties and formation of new ties for tailored support. Soc Sci Med. 2015;1(134):59-65.

5. Hill M, Huff A, Chumbler N. Variation in networks and forms of support for care-seeking across the HIV care continuum in the rural southeastern United States: variation in social support for HIV care. J Rural Health. 2018;34(1):71-9.

6. Latham-Mintus K. A friend in need? Exploring the influence of disease and disability onset on the number of close friends among older adults. J Gerontol: Ser B. 2019;74(8):e119-24.

7. Perry BL, Pescosolido BA. Social network activation: the role of health discussion partners in recovery from mental illness. Soc Sci Med. 2015;1(125):116-28.

8. Perry BL, Pescosolido BA. Functional specificity in discussion networks: the influence of general and problem-specific networks on health outcomes. Soc Netw. 2010;32(4):345-57.

9. Perry BL, Pescosolido BA. Social network dynamics and biographical disruption: the case of "first-timers" with mental illness. Am J Sociol. 2012;118(1):134-75.

10. Perry BL. Symptoms, stigma, or secondary social disruption: three mechanisms of network dynamics in severe mental illness. J Soc Pers Relatsh. 2014;31(1):32-53.

11. Small ML, Sukhu C. Because they were there: access, deliberation, and the mobilization of networks for support. Soc Netw. 2016;1(47):73-84.

12. Emlet CA. An examination of the social networks and social isolation in older and younger adults living with HIV/AIDS. Health Soc Work. 2006;31(4):299-308. 
13. Emlet CA. Experiences of stigma in older adults living with HIV/AIDS: a mixed-methods analysis. AIDS Patient Care STDs. 2007;21(10):740-52.

14. Shippy RA, Karpiak SE. Perceptions of support among older adults with HIV. Res Aging. 2005;27(3):290-306.

15. Takada S, Nyakato V, Nishi A, O’Malley AJ, Kakuhikire B, Perkins JM, Bangsberg DR, Christakis NA, Tsai AC. The social network context of HIV stigma: population-based, sociocentric network study in rural Uganda. Soc Sci Med. 2019;1(233):229-36.

16. Poindexter C, Shippy RA. Networks of older new yorkers with HIV: fragility, resilience, and transformation. AIDS Patient Care STDs. 2008;22(9):723-33.

17. Brennan-Ing M, Seidel L, Karpiak SE. Social support systems and social network characteristics of older adults with HIV. In: InHIV and aging. Karger Publishers; 2017, vol. 42, p. 159-172.

18. Hall BJ, Sou KL, Beanland R, Lacky M, Tso LS, Ma Q, Doherty M, Tucker JD. Barriers and facilitators to interventions improving retention in HIV care: a qualitative evidence meta-synthesis. AIDS Behav. 2017;21(6):1755-67.

19. Nobre NR, Kylmä J, Kirsi T, Pereira M. Social networks of older adults living with HIV in Finland. AIDS Care. 2016;28(2):186-90.

20. Groft JN, Vollman AR. Seeking serenity: living with HIV/AIDS in rural Western Canada. Rural Remote Health. 2007;7:677.

21. Zhang T, Cao W, Lv J, Wang N, Reilly KH, Zhu Q, Li L. Size, composition, and strength of ties of personal social support networks among adult people living with HIV/AIDS in Henan and Beijing, China. AIDS Behav. 2012;16(4):911-9.

22. Zhang Y, Fuller-Thomson E, Anne Mitchell C, Zhang X. Older adults with HIV/AIDS in rural China. Open AIDS J. 2013;7(1):51-7.

23. Rice E, Comulada S, Green S, Arnold EM, Rotheram-Borus MJ. Differential disclosure across social network ties among women living with HIV. AIDS Behav. 2009;13(6):1253-61.

24. Zhang Y, Fuller-Thomson E, Anne Mitchell C, Zhang X. Older adults with HIV/AIDS in rural China. Open AIDS J. 2013;7(1):51-7.

25. Shippy R, Cantor M, Brennan M. Social networks of aging gay men. J Men's Stud. 2004;13(1):107-20.

26. Pakenham KI. Specification of social support behaviours and network dimensions along the HIV continuum for gay men. Patient Educ Couns. 1998;34(2):147-57.

27. Shippy RA, Karpiak SE. The aging HIV/AIDS population: fragile social networks. Aging Ment Health. 2005;9(3):246-54.

28. Schrimshaw EW, Siegel K. Perceived barriers to social support from family and friends among older adults with HIV/AIDS. J Health Psychol. 2003;8(6):738-52.

29. Moore AR. Older people living with HIV/AIDS (OPLWHA) in Lomẻ, Togo: personal networks and disclosure of serostatus. Ageing Int. 2013;38(3):218-32.

30. Ssali SN, Atuyambe L, Tumwine C, Segujja E, Nekesa N, Nannungi A, et al. Reasons for disclosure of HIV status by people living with HIV/AIDS and in HIV care in Uganda: an exploratory study. AIDS Patient Care STDs. 2010;24(10):675-81.

31. Zang C, He X, Liu H. Selective disclosure of HIV status in egocentric support networks of people living with HIV/AIDS. AIDS Behav. 2015;19(1):72-80.

32. Klopper C, Stellenberg E, Van der Merwe A. Stigma and HIV disclosure in the Cape Metropolitan area, South Africa. Afr J AIDS Res. 2014;13(1):37-43.

33. Hellstrom Y, Hallberg IR. Perspectives of elderly people receiving home help on health, care and quality of life. Health Soc Care Commun. 2001;9(2):61-71.

34. Wolff JL, Spillman BC, Freedman VA, Kasper JD. A national profile of family and unpaid caregivers who assist older adults with health care activities. JAMA Intern Med. 2016;176(3):372-9.
35. Wellman B. The network community: an introduction. In: Networks in the global village; 1999 . p. 1-48.

36. Goldman AW, Cornwell B. Social network bridging potential and the use of complementary and alternative medicine in later life. Soc Sci Med. 2015;1(140):69-80.

37. Joint United Nations Programme on HIV/AIDS. Miles-to-go: closing the gaps, breaking barriers, righting injustices: Global AIDS update 2018. Geneva; 2018. Accessed 21 Jan 2020.

38. Kahn K, Collinson MA, Gómez-Olivé FX, Mokoena O, Twine $\mathrm{R}$, Mee P, et al. Profile: agincourt health and socio-demographic surveillance system. Int J Epidemiol. 2012;41(4):988-1001.

39. Gómez-Olivé FX, Montana L, Wagner RG, Kabudula CW, Rohr JK, Kahn K, et al. Cohort profile: health and ageing in Africa: a longitudinal study of an INDEPTH community in South Africa (HAALSI). Int J Epidemiol. 2018;47(3):689j-90j.

40. Harling G, Perkins JM, Gómez-Olivé FX, Morris K, Wagner RG, Montana L, Kabudula CW, Bärnighausen T, Kahn K, Berkman L. Interviewer-driven variability in social network reporting: results from Health and Aging in Africa: a longitudinal study of an INDEPTH community (HAALSI) in South Africa. Field Methods. 2018;30(2):140-54.

41. Perry BL, Pescosolido BA, Borgatti SP. Egocentric network analysis: foundations, methods, and models. Cambridge: Cambridge University Press; 2018.

42. Marin A, Wellman B. Social network analysis: an introduction. In: Scott PJP, Carrington PP, editors. The SAGE handbook of social network analysis. Thousand Oaks: SAGE Publications; 2011. p. $11-25$.

43. Cornwell B, Schumm LP, Laumann EO, Graber J. Social networks in the NSHAP study: rationale, measurement, and preliminary findings. J Gerontol Ser B: Psychol Sci Soc Sci. 2009;64(suppl_1):i47-55.

44. Cornwell B. Good health and the bridging of structural holes. Soc Netw. 2009;31(1):92-103.

45. Riumallo-Herl C, Canning D, Kabudula C. Health inequalities in the South African elderly: the importance of the measure of social-economic status. J Econ Ageing. 2019;1(14):100191.

46. Harling G, Morris KA, Manderson L, Perkins JM, Berkman LF. Age and gender differences in social network composition and social support among older rural South Africans: findings from the HAALSI study. J Gerontol: Ser B. 2020;75(1):148-59.

47. Rosenberg MS, Gómez-Olivé FX, Rohr JK, Houle BC, Kabudula CW, Wagner RG, Salomon JA, Kahn K, Berkman LF, Tollman SM, Bärnighausen T. Sexual behaviors and HIV status: a population-based study among older adults in rural South Africa. J Acquir Immune Defic Syndr. 1999;74(1):e9.

48. Schwartz E, Litwin H. Social network changes among older Europeans: the role of gender. Eur J Ageing. 2018;15(4):359-67.

49. Upenieks L, Settels J, Schafer MH. For everything a season? A month-by-month analysis of social network resources in later life. Soc Sci Res. 2018;1(69):111-25.

50. Royston P. Multiple imputation of missing values: update of ice. Stata J. 2005;5(4):527-36.

51. von Hippel PT. Regression with missing Ys: an improved strategy for analyzing multiply imputed data. Sociol Methodol. 2007;37(1):83-117.

52. Campbell T, Griffiths J. "I can still be happy, I can still get my life again": psychological interventions with children, young people and families living with HIV in the United Kingdom. In: Liamputtong $\mathrm{P}$, editor. Cross-cultural research in health, illness and well-being. Children and young people living with HIV/AIDS: a cross-cultural perspective. Cham: Springer; 2016. p. 399-420.

53. Laryea M, Gien L. The impact of HIV-positive diagnosis on the individual, part 1: stigma, rejection, and loneliness. Clin Nurs Res. 1993;2(3):245-63. 
54. Obermeyer CM, Baijal P, Pegurri E. Facilitating HIV disclosure across diverse settings: a review. Am J Public Health. 2011;101(6):1011-23.

55. Iwelunmor J, Airhihenbuwa CO, Okoror TA, Brown DC, BeLue R. Family systems and HIV/AIDS in South Africa. Int Q Commun Health Educ. 2008;27(4):321-35.

56. Gaskins S, Payne Foster P, Sowell R, Lewis T, Gardner A, Parton J. Reasons for HIV disclosure and non-disclosure: an exploratory study of rural African American men. Issues Ment Health Nurs. 2011;32(6):367-73.

57. Ostrom RA, Serovich JM, Lim JY, Mason TL. The role of stigma in reasons for HIV disclosure and non-disclosure to children. AIDS Care. 2006;18(1):60-5.
58. Pescosolido BA. Beyond rational choice: the social dynamics of how people seek help. Am J Sociol. 1992;97(4):1096-138.

59. Perry BL. Coming untied? Narrative accounts of social network dynamics from first-time mental health clients. Sociol Health Illness. 2012;34(8):1125-39.

Publisher's Note Springer Nature remains neutral with regard to jurisdictional claims in published maps and institutional affiliations. 